\title{
IN-TOUCH DIGITAL PLATFORM FOR UNCONVENTIONAL LEARNERS
}

by

\author{
Angelique Patrice Paul \\ Bachelor of Design, OCAD University, 2016 \\ A Major Research Project \\ presented to Ryerson University \\ in partial fulfillment of the \\ requirements for the degree of \\ Master of Digital Media \\ in the Program of Digital Media
}

Toronto, Ontario, Canada, 2017

(c) Angelique Paul 2017 


\section{AUTHOR'S DECLARATION}

AUTHOR'S DECLARATION FOR ELECTRONIC SUBMISSION OF A MRP

I hereby declare that I am the sole author of this MRP. This is a true copy of the MRP, including any required final revisions.

I authorize Ryerson University to lend this MRP to other institutions or individuals for the purpose of scholarly research.

I further authorize Ryerson University to reproduce this MRP by photocopying or by other means, in total or in part, at the request of other institutions or individuals for the purpose of scholarly research.

I understand that my MRP may be made electronically available to the public.

Signed,

Angelique Paul 


\section{IN-TOUCH DIGITAL PLATFORM FOR UNCONVENTIONAL LEARNERS Master of Digital Media, 2017 \\ Angelique Patrice Paul \\ Master of Digital Media, Ryerson University}

\section{ABSTRACT}

In-Touch is an adaptive learning technology, which extends the learning experience beyond the classroom hours and environment for unconventional learners. It serves as a safe online space for students to receive customized help from their teachers. It also mediates and promotes conversation between parents and teachers. In-Touch integrates three elements crucial to promoting success of unconventional learners: ondemand help, student-centered approach, and confidence-building. For the purpose of the study, unconventional learners were defined as someone who does not learn in the methods that are currently offered in traditional classrooms. The design of In-Touch is based on a pilot study that considered the needs of parents and teachers who are raising and teaching unconventional learners. 


\section{ACKNOWLEDGEMENTS}

I would like to thank Alventina Naumova and Nicholas Goso for being my mentors, my cheerleaders, therapists, teachers and friends. Thank you for your believing in me and for believing in this project. I would also like to thank the friends l've made at OCAD University and in the 2015 MDM Cohort for their kindness, input, and laughter. And to my family for always being my best critics and loudest supporters. 
For Sara 


\section{TABLE OF CONTENTS}

Author Declaration

Abstract iii

Acknowledgements

Dedication $\quad$ V

Table of Contents $\quad$ vi

List of Figures vii

List of Images viii

$\begin{array}{ll}\text { Introduction } & 1\end{array}$

Models of Communication 4

On-Demand Help 5

$\begin{array}{ll}\text { Student Centered Approach } & 6\end{array}$

$\begin{array}{ll}\text { Emotional Aspect } & 10\end{array}$

$\begin{array}{ll}\text { Analytical Framework } & 12\end{array}$

$\begin{array}{ll}\text { Review of other Platforms } & 13\end{array}$

$\begin{array}{ll}\text { Project Plan } & 14\end{array}$

$\begin{array}{ll}\text { Methods of Research } & 14\end{array}$

$\begin{array}{ll}\text { Research Findings } & 17\end{array}$

$\begin{array}{ll}\text { Product Development } & 19\end{array}$

$\begin{array}{ll}\text { Functionality } & 24\end{array}$

$\begin{array}{ll}\text { Conclusion } & 26\end{array}$

$\begin{array}{ll}\text { Appendix } & 28\end{array}$

Work Cited 35 


\section{LIST OF FIGURES}

Figure 1- The Shannon and Weaver Model of Communication 4

Figure 2- The In-Touch Model of Communication $\quad 5$ 


\section{LIST OF IMAGES}

Image 1- Share a Chalkboard

Image 2- Goals

Image 3-Announcements

24 


\section{Introduction}

This Major Research Project unpacks the idea for the design of an online learning platform, which extends the learning environment of a classroom into an intimate and safe space, customized around the special needs of unconventional learners. While the Toronto District School Board (TDSB) works to provide fair access to learning for students of varying needs, the funding for special needs programmes is not sufficient to satisfy the demand for them. Students, whose struggles are less obvious, often have to wait longer for the help they need. According to Toronto District School Board: Financial Facts \& Expenditure Trends: Funding for Ministry Initiatives in the 2013-2014 school year Support with Special Needs, kindergarten to grade 12 received $\$ 135,251$ and funding for tutors in the classroom received $\$ 60,000$ (p.13).

For the purpose of my project, I define an unconventional learner as someone who learns and retains information through methods that are not readily accommodated in the current classroom experience as offered in conventional classrooms. Through my investigation, it is clear that the TDSB does not accommodate students that learn unconventionally. Rather, all students that are considered to learn outside "the norm", are categorized under the term "learning disability." According to the Learning Disabilities Association of Ontario (2015), learning limitation (LL) is the largest disability, affecting $69.3 \%$ of children with a learning disability, and $3.2 \%(121,080)$ of all children from age 5-14. Learning limitation (LL) is defined by the Learning Disabilities Association of Ontario as "difficulty learning due to the presence of a condition, such as 
attention problems, hyperactivity or dyslexia, whether or not the condition was diagnosed by a teacher, doctor or health professional."

Thus, from the point of view of the Learning Disabilities Association of Ontario, the group that I define as alternative learners could potentially be categorized as having an LL. Proper assessment from certified professional is not required to identify them as such. While there is a distinct line between unconventional learning and learning disability, the Learning Disabilities Association of Ontario is using the term "learning limitation" to categorize all of those who do not fit within the norm. This potentially expands the demographic of my product.

In-Touch addresses the wide range of abilities and learning styles that is suggested by the definition of alternative learners by being economically efficient, and addressing a wide range of abilities that fall under the description of an unconventional learner. Further, it allows for better communication between parents and teachers, which is something that the TDSB is not directly addressing, but is an important aspect that became apparent through my research. This platform enables and encourages learning by creating an online space that accommodates specific educational objectives and needs. It is also a safe environment that allows teachers, parents and students to openly discuss the learning process and objectives. Finally, the interactive design of InTouch takes into account a range of learning styles. The design of In-Touch was informed by the results of a pilot study I have conducted, in which I have carried out 7 in-depth unstructured interviews with Toronto's teachers and parents who are teaching 
and raising students that I describe as "alternative learners." Because of what I have learned in the interviews, I have incorporated an element that allows students and teachers to upload visuals, draw on the screen and listen to an explanation of the problem. Thus, In-Touch allows for a variety of way of engaging both with the material and the technology. Further, the issue of self-confidence and anxiety came through strongly in the interviews. In-Touch addresses that by allowing unconventional learners to ask questions in private without fear or hesitation at a scheduled time; receive more feedback, more explanation, and additional assignments developed specifically for them. Finally, In-Touch allows parents to take a more active part in the child's learning process by creating an additional channel of communication with the instructors. I analyze my findings in more detail later in this paper.

The traditional teaching approach popular until recently suggested that a teacher stood in front of a classroom delivering material. This method of delivering information failed to resonate with students who did not learn through this linear method of teaching. According to "Education and Inspiration for General Practice" by Alexander Rolfe and Brad Cheek (2012), there are several learning styles including visual/verbal, visual/nonverbal, kinaesthetic, and auditory/verbal, all of which were not addressed by the standard method of teaching (p.176) However, teachers are no longer lecturers, but facilitators in the classroom. In this digital age parents are seeking methods beyond the classroom to aid their children that learn unconventionally through online resources or afterschool programs. However, the issue persists, because the educational system continues to fail to meet the needs of those who learn unconventionally. As a part of my 
research I have investigated the ways in which the TDSB accommodates unconventional learners, studied what is necessary for a successful learning experience for those who learn unconventionally and interviewed teachers, tutors and parents of unconventional learners to support my investigation. Through my research, it is clear that the TDSB alternative schools do address alternative styles of learning through teaching but mainly focus on creating a safe space for students who belong to minority groups, or have a non-traditional lifestyle. Furthermore, in terms of educational support, the TDSB's concern is directed at those with a learning disability while excluding and almost ignoring the idea and reality of an unconventional learner while failing to address the student as an individual. In-Touch will assist in extending the learning process beyond classroom hours, that will enable teachers to be available to students in way that are individualized and thus empowering, while being cost-effective and accessible.

\section{Theoretical Framework}

\section{Models of Communication}

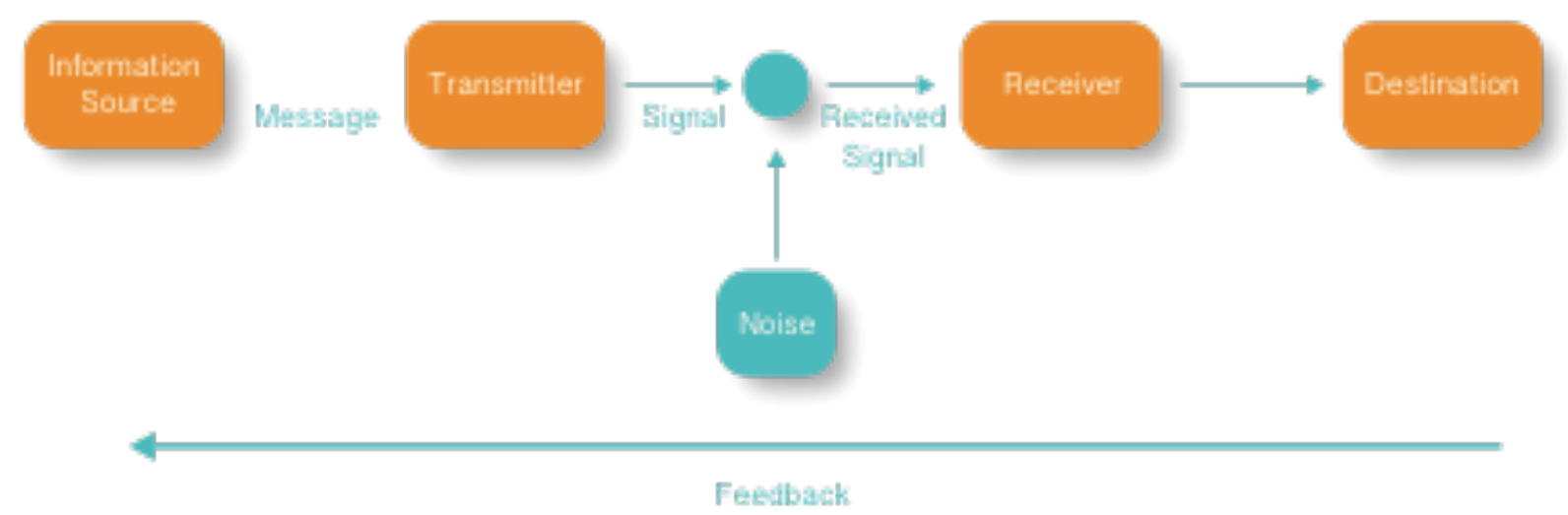

Figure 1: The Shannon and Weaver Model of Communication (redrawn by Angelique Paul, see Appendix A for original) 
The Shannon and Weaver's (1948) Model of Communication illustrates the way in which information travels from the sender to the receiver. According to Communication Models for the Study of Mass Communication by Denis Mcquail and Sven Windahl (1993), the information source or the sender creates a message that is formed into a signal by the transmitter. Next, the signal is altered to suit the

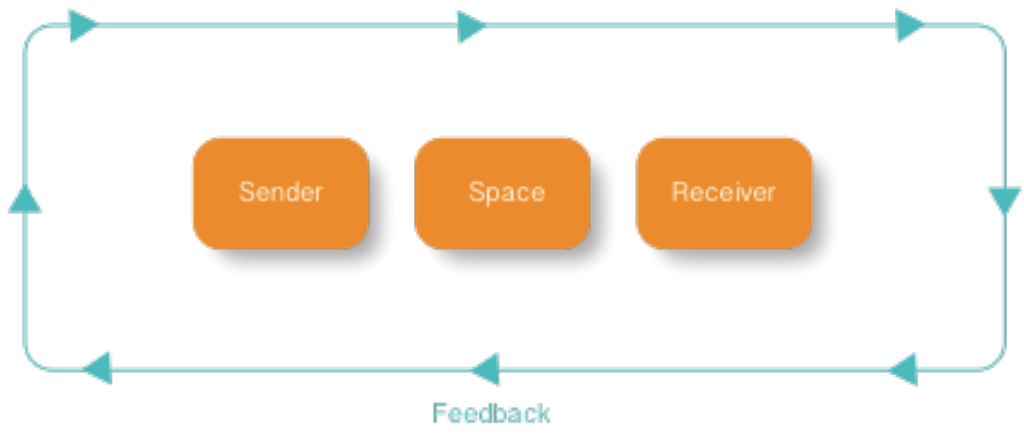

Figure 2: The In-Touch Model of Communication channel which leads to the receiver. The receiver reconstructs the message from the signal and delivers it to the destination. In this project, I consider a different way of conceiving of the process of communication. In-Touch enables communication and learning by defining the platform as a space, rather than a channel. In-Touch is a platform that involves the parent, teacher and the student. Unlike the Shannon and Weaver (1948) model that implements a one-way approach to communication, the model that represents In-Touch depends on open-ended and balanced communication between all of the parties. All parties in this process are able to contribute to the process. The success of the process of communication and the definition of success depends on involvement of all parties.

Designing a space where all parties are equally involved creates a continuous loop of sending and receiving that does not depend on a sole sender and receiver. 
Additionally, In-Touch, creates an open-ended and balanced space of participation of all those involved and allows the sender and receiver the opportunity to truly listen to make learning possible.

In this thesis, I substantiate the design of the In-Touch platform. I begin by outlining the specific cornerstone ideas that have informed the design objectives for the project. Further, I provide a literature review to support three essential elements that are vital to the function and purpose of In-Touch. I then proceed to review other platforms to inform the design decisions of In-Touch, and in the final section, I explain my findings.

\section{On-Demand Help}

"In Help Seeking and Help Design in Interactive Learning Environments", Aleven, Stahl, Schworm, Fischer and Wallace (2003) explain the use of on-demand learning. They suggest, that:

In general, different ILEs [Interactive Learning Experience's] offer many different types of support to learners; however, almost without exception, they offer ondemand help. By on-demand help we mean information actively solicited by the learner and provided by the system, for the purpose of helping learners learn better with the ILE. Thus, we focus on help functions designed to support learning, not task performance per se. (p.277)

This shift in the perspective as established by Aleven et al (2003) was crucial to how I approached certain aspects of my design. The teacher and student are not focused on solving a problem, but their focus is towards identifying individual pathways that would allow the student to make sense of the problem on their own terms. In order 
to extend the learning experience, we must implement the use of on-demand help that drives the learning experience forward by creating opportunities for interactive learning. If students are struggling with their work outside of the classroom setting, they will be able to seek help through a form of communication that suits them and receive assistance from their teacher that will help them arrive at the solution. Aleven et al (2003) address on-demand learning supported by a computer system. However, a computer on-demand service does not have the intuition and understanding of a human teacher and inhibits students who cannot communicate their problem area clearly. By merging the teacher with the affordances of technology In-Touch will be able to facilitate the need of on-demand learning at a scheduled time.

\section{Student-Centered Approach}

The student centered approach is crafting the method of teaching to facilitate the learning style of the student, further explained in The Greenwood Dictionary of

\section{Education:}

Student-centered instruction [SCl] is an instructional approach in which students influence the content, activities, materials, and pace of learning. This learning model places the student (learner) in the center of the learning process. The instructor provides students with opportunities to learn independently and from one another and coaches them in the skills they need to do so effectively. (Collins and O'brien, 2003, p.338)

The student-centered approach has proven to be more successful and fruitful when teaching those who learn through alternative methods. Rebecca Lynn Rosenquist (2000), in "A Comparison of Learning Styles Between Alternative and Traditional 
Educators in the State of lowa", discusses the advantages of a comfortable relationship between the student and teacher in alternative learning programs. The article explores the effects of positive teacher and student interaction within the frame of alternative schooling and at-risk students. Rosenquist (2000) addresses the importance of an understanding instructor and an open line of communication, a factor that I considered in the design of In-Touch in order to create a welcoming and encouraging atmosphere for unconventional learners. Rosenquist (2000) further explains that the role of a teacher at an alternative school is different than that of a teacher at a traditional school. Alternative educators are selectively chosen to handle alternative learning styles, while partaking in an encouraging and respectful relationship with their students. To illustrate the importance of this relationship Rosenquist (2000) clarifies that studies have proven that students favor teachers that invest into a one-on-one relationship by fulfilling the role of a mentor rather than a distant instructor. Rosenquist (2000) explains that this approach to the relationship is more fruitful as it encourages the learning process and equips the students with confidence and security.

Formative assessment is the implementation of frequent evaluation, used to better understand the needs of the student and adapt the teaching method based on the student's strengths and weaknesses. Stephen and Jan Chappuis (2007) explain in their article "Educational Leadership: Informative Assessment":

Both the teacher and the student use formative assessment results to make decisions about what actions to take to promote further learning. It is an ongoing, dynamic process that involves far more than frequent testing, and measurement of student learning is just one of its components (p. 14-19). 
By applying formative assessment, the teacher and the student can create a continuous feedback loop in order to identify areas of strength and weaknesses to move forward. According to Nora Bakula (2010) in "The Benefits of Formative Assessment for Learning and Teaching", formative assessment requires the continuous involvement of the teacher and student; the involvement of both parties creates a learning environment that has been adapted to better suit the student by encouraging questions and anticipating the next step forward. This type of assessment also facilitates a feedback loop that allows the instructor to adapt their style of teaching to best fit the needs of the student by identifying strengths and weaknesses.

In contrast, summative assessment occurs after an extended period of learning, and is used for the benefit of the teacher and school rather than the student's learning experience. In addition, students are given feedback without the prospect of reassessment and are measured against a specific standard.

A report by the Centre for Education and Research Innovation's entitled "Assessment for Learning: Formative Assessment" (2006) addresses the "What Works" case study that implemented the use of formative assessment. Through this study, teachers were able to monitor student learning and both parties were able to identify areas of success as well as setbacks. This approach resulted in a more successful and individualized approach to learning that was better suited for the student's individual learning styles. Although formative can be positioned as the better approach and summative as the less effective assessment, Sarah Earle explains in Formative and 
summative assessment of science in "English Primary Schools: Evidence from the Primary Science Quality Mark" (2014), that the use of formative and summative assessment collectively has the potential to better the learning experience. By providing and applying feedback through the learning process it will better the outcome of a summative assessment, strengthen the understanding of the student, while providing the student the opportunity to apply the tools they've learned through In-Touch when they are in the classroom setting. Formative assessment would be integrated into the design of In-Touch by applying an ongoing process that is reflected in the ways goals are set weekly. When the student sets their goal at the beginning of the week the teacher and parent monitor the learning process each day to evaluate whether or not the method of teaching is affecting the student's ability to understand their homework. The students' progress will inform the teacher and parent whether or not the method of teaching is helpful or requires an adaption to better suit the student. In addition, establishing a feedback loop between the teacher and student is an integral aspect of formative assessment. Therefore, the messaging center is a method of communication that will allow the teacher to have an open line of communication with the student and parent.

\section{Aid in Emotional Aspects}

Because of my own experience as an unconventional learner, I am aware of the emotional strain that comes with it. When one learns in ways that are considered different, feelings of loneliness and frustration form an emotional burden. Tanis Bryan, Karen Burstein, and Cevriye Ergul (2004) explain in their article "The Social-Emotional 
Side of Learning Disabilities: A Science-based Presentation of the State of the Art," the effects that both positive and negative emotions have on learning. The article explains that feelings of positivity; happiness, acceptance and understanding increase the ability to retain information and enhance self-confidence. However, children who learn alternatively are more likely to experience negative emotions of anxiety and fear than children that learn through conventional methods .Further explained by Jason M.

Nelson and Hannah Harwood (2010) in their article "Learning Disabilities and Anxiety: A Meta-Analysis,"

A large body of research has indicated that high levels of anxiety have deleterious effects on performance on cognitive and academic tasks. High levels of anxiety introduce task-irrelevant cognitions into the limited storage component of the information processing system. This anxiety-produced distracting information, disrupts attentional focus and consumes space in working memory, resulting in inefficient information processing. (p.4)

With this in mind, there is an opportunity to utilize In-Touch's aspect of communication and position the platform to assist in the emotional strain of unconventional learning. The article explains the dominance of emotions in learning unconventionally. This insight, my interviews with teachers and parents, as well as my own experiences have guided me in designing the platform. Sometimes, by not understanding a concept that everyone in your surrounding seems to grasp can ignite a fear of looking unintelligent or inferior to your classmates. By providing a space for students to ask questions without fear of judgement, and notifications of progress, unconventional learners can approach learning with a sense of confidence. These 
features will play an integral role in building the student's confidence and continuously forming the fundamental bond between instructor and student.

\section{Analytical Framework}

When designing anything for users it is important to remember that the design must provide a good user experience. If the design is confusing, frustrating or has poor navigation the purpose of the platform fails before it can fulfill its use. In this section, I will draw on my discussion thus far to unpack ideas that informed my project design. In terms of on-demand help I need to ensure that both the teacher and student receive notifications to let them know a question has been asked or answered. By merging the convenience of technology with an understanding teacher, In-Touch is able to service the student immediately in a way that can cater to the specific student needs. The platform allows students to communicate with the teacher in a way that suits their style of learning. In-Touch works with visual, audio, kinaesthetic, and verbal learners by allowing drawing, voice messaging and pod casts. In many cases alternative learners cannot pinpoint the exact area that is causing them difficulty. By implementing the combination of formative and summative assessment into the design of the platform we can make sure that the teacher can communicate clearly and the student has the means to articulate their area of difficulty by drawing, taking pictures of the question, or sending a voice recording to their teachers. This approach will effectively apply the use of formative assessment by continuous feedback and teaching adaption and provide students the tools to apply to their homework, and classwork. In addition, as mentioned before, students that learn unconventionally are more likely to experience emotions of 
anxiety in comparison to students who learn conventionally (Bryan et al.,2004). With that in mind, I designed the platform to provide the kinds of progress reports as well as messages of accomplishment that will instill confidence as depicted in Figure 4.

\section{Review of other platforms}

In this section I review different kinds of technology to contextualize In-Touch to learn from the strengths and weaknesses of other platforms.

\section{Remind}

Remind allows for one-way communication between teachers, students and parents via text in order to inform students of deadlines, and upcoming assignments. This app involves both the parents and the students in the learning process. However, this app uses one-way communication which does not allow two-way dialogue; a factor that is necessary to keep both parents and students involved in the entire process of learning.

\section{Talking Mats Lite}

This app assists children and adults with communication and learning disabilities to express their thoughts and improve their communication skills using a variety of symbols. The use of symbols for navigation and communication could be beneficial for In-Touch because it could be an easier method of communicating between younger students and teachers. This app facilitates communication for those who struggle with expressing their thoughts. I plan to learn from the platform and incorporate the use of symbols to assist students in communicating with their teachers. 


\section{My Medical}

Only available on IOS, this app allows users to archive their complete medical history and tracks and record vital information pertaining to test results and performance. This feature of tracking patterns and recording information would be beneficial to track and display student progress and allow both teachers, students and parents to view areas of strengths and weakness.

\section{Project Plan}

In order to create In-Touch I needed to go through a series of stages to ensure this product meets the needs and desires of my target market. In identifying pinnacle stages in app development, I drew on New Relic's report: " 5 Key Phases in Creating a Successful Mobile App"(n.d.). Although this article outlines pivotal steps for app development, I believe the several sub-stages that are mentioned are essential to developing an online platform that meets the needs of the consumer. To depict the steps that I plan to take, I have used their breakdown to explain the journey towards InTouch.

\section{Criteria for Success}

Goal: I would first need to determine what success looks like for my app.

Will it be a useful tool for the parent/child/teacher?

Will it be an effective tool in learning progression? 
Will it fulfill its purpose as an identifier of strengths and weaknesses, a useful guide that helps the teacher articulate a student centered approach and an aid in emotional support for the student?

Platform: Secondly, I would need to consider user accessibility.

Will the app be accessible on both Android and iOS?

Is the interface adjustable to all mobile devices; such as tablets and phones?

Purpose: The purpose of app requires much consideration, and to do that I would have to understand my main user; the teacher, the student and potentially the parent.

Are the functionalities of the app exactly what the target needs or wants?

Does this target communicate through apps?

Would this be an effective and convenient tool of communication for all three parties?

Competition: In order to ensure the effectiveness of my app I would have to know my competition and see what is and what is not working in the current market.

Identify competition.

Investigate their strengths and weaknesses.

Explore what my app can improve on in the best interest of the user. 
Through these steps within the Strategy phase I will be able to identify a business model that will work well for my platforms creation. This information will allow me to clearly identify the problem, develop a solution and create a consumer profile.

\section{Methods of Research}

The goal of my research was to gather insights from the parents and teachers of unconventional learners in order to make informed design decisions. To satisfy the requirements of the Research Ethics Board (REB) all the teachers and tutors that were involved in the one-on-one interview were unaffiliated with a school board. In addition, teachers were required to have had two years of teaching experience with unconventional learners. To conduct my research, I first had to go through the process of gaining approval from the Ryerson Ethics Board of Research. Throughout the process, I was able to distill the intent of my research, and clearly define who I would be talking to and what questions would provide me with substantial information and data to move forward with my project. I developed a series of questions in order to gather data to inform the design of my prototype, while involving users in the design process.

The objectives of these questions were to inform the design decisions of InTouch and help me arrive at an insight that would craft this platform to better facilitate the needs of the parent, teacher and student. Through my past research in user experience, I have learned that it is vital to seek the guidance of the users while in the research and design process. With that being said, I conducted seven in-depth unstructured interviews with parents and teachers of unconventional learners to get an 
understanding of what they felt the platform needed. While these interviews were unstructured, I had a list of questions that had to be covered in order to keep data comparable. Through much revision, I was able to create a series of questions that asked the both teacher and parents to reflect on aiding their student or child through the learning process. The questions that I used for the interview process circulated around the three main features that formed the framework of In-Touch philosophy: on-demand help, the student centered approach and the emotional aspect of learning unconventionally. My goal was to understand what, as a designer, I could do specifically in order to apply these three ideas in ways that would be most useful. With this knowledge, I was able to make informed design decisions that were grounded in fact and experience.

The semi-structured interviews provide opportunities for less bias results and allowed the interviewees to answer questions on their own terms. The questions were openended in order to create conversational-like atmosphere, and get a deeper answer from the parents and teachers. My REB approval used the term "semi-structured" which allowed for some flexibility in the way in I conducted the interviews, in the appendix I have provided the list of questions (See Appendix B).

\section{Research Findings}

After receiving approval for my research from the REB, I was able to conduct my interviews with a total of seven participants consisting of teachers and tutors that have two years teaching experience with male and female unconventional learners between 
the ages of seven and thirteen years of age, and the parents of male and female unconventional learners between the ages of seven and thirteen years of age. The average class size of the teachers interviewed was approximately twenty students, whereas the tutors used a one-on-one approach. In addition, the parents involved in the interview process had an average of two children that consisted of one unconventional learner and one conventional learner. While I realized it would be beneficial to interview students, I could not accomplish that within the framework of my current project. If I were to interview students their input would be the step that I would take in moving the project forward.

In addition, I decided to interview the previously mentioned participants because I wanted to conduct user-centered research. According to "User-centered Design Through Learner-Centered Instruction" by Burçak Altay,

User-centered approaches to design enhance a wider range of diverse users to use and accept products/spaces, increasing productivity and reducing errors (Zoltowski, Oakes, and Cardella 2012). The approach ensures more relevant design outcomes that go beyond mere utilitarian functionality, thus encourages user's emotional engagement and motivation by bringing their own conceptualizations and meanings to the experience (Krippendorff 2004; McDonagh and Thomas 2010). (p.139)

With this in mind, I decided that interviewing and involving the participants would ensure that In-Touch was designed with functions that would service and benefit the needs of the consumer. Through a series of open-ended questions, I gathered information and was able to extract useful insights that would affect the design of the platform. I provided all participants with a thorough explanation of the platform. When summarizing the findings, and discussing how it informed my decision making, I analyzed the 
interviews and attempted to tease out common themes pertaining to the specific needs of teachers and parents.

\section{Product Development}

The research done for this project was used to determine general themes in the concerns expressed by the teachers and parents. These themes were dedication of the teacher, parent and teacher communication and involvement, student engagement and interaction.

\section{$\underline{\text { Teacher Dedication }}$}

It was evident through my interviews with the teachers that dedication to their job and children was an integral element when teaching students that learn unconventionally. One of the participants explained,

You have to love your subject and love the kids...don't think that you know everything, be open to learning from your students. If you don't know that, you shouldn't be a teacher. (Interviewee A)

This participant continued to explain that the teacher must be invested in teaching their students and realize that they are not teaching the child in order for the student to move onto the next grade, but equipping the student with the tools to succeed and prosper in life,

The teacher has to know that they're not teaching the child to just pass the subject but they're teaching the child to prepare for life...the student has to convince me that they're right, they have to stand their ground with me, and [they need to] have the confidence to know and say that they're correct.(Interviewee B) 
Through this understanding I was able to make an informed design decision for InTouch by stressing the importance of the teacher and student bond by creating the terms of educational process together. By establishing criteria for success and setting goals the teacher can make the process truly successful through listening to the student and adapting his or her teaching to accommodate the students learning style. The platform facilitates three users: the teacher, the student and the parents and provides video calling and a messaging center, that allows the student and teacher to speak about the learning process on a regular basis, while providing the teacher and parent the opportunity to have active role in the learning experience seen in Image 1 . While

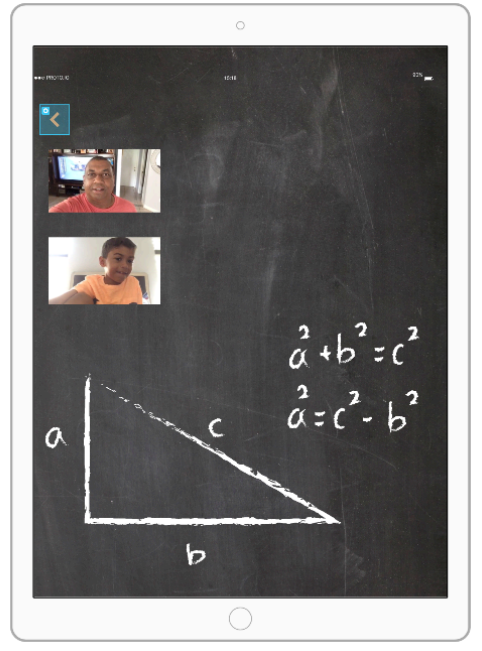

Image 1-Share a Chalkboard creating the design I realized that assisting students of all different learning styles required more than a messaging center and schedule video sessions, this became apparent to me when I recalled one participant's response to initial explanation of the platform,

My daughter doesn't learn by one particular learning style; I would say visual learning doesn't work well for her but she learns from a mixture of other learning styles. (Interviewee A)

send audio files to aid audio learners and created the option of sharing a chalkboard during the scheduled video session in order to assist visual learners. 


\section{$\underline{\text { Parent and teacher communication and involvement }}$}

During the interview process I asked interviewee D if they were involved in their child's learning process, to which they responded

Truthfully, no, but I would want to be involved because it's important. I would really like to know how my son learns because I think he really does view things differently than the average person. (Interviewee D)

As the interviews continued, both parties explained the importance of maintaining an open line of communication between the teacher and the parent,

One thing that I find in this school system is that the teacher's do not react in the community. Where I taught all the parents of my students knew me by name. Communication between the teacher and parent is important to the child's learning. (Interviewee B)

In the beginning stages, I designed In-Touch with a section called the "clubhouse". In this area you would find a messaging center, announcements and a log of past information. However, participants from both groups explained that setting goals had proven to be an effective method for their students and children. They continued to explained that it was essential that both the teacher and the parent played an active role in setting the goals as well as allowing the student to set incentive that would encourage their desire to reach the set goal.

She tried to get us to set goals, for example, then she would comment on how he did, but it lasted three weeks. It was unsuccessful because I wasn't pressing him to pick out the issue and work on it, and also I didn't hear much from his teacher after that. She commented the first week, then the second week was less, and then it stopped working. Also, there was no reward when my son was setting the goal, these are kids they need to be striving for something. There was no real reward set for him, it was like do this, but then what? Maybe that's partially why it fell off, he didn't really have anything to work towards. I didn't give him a reward 
and the teacher didn't give him one either. It was just try to do better. (Interviewee A)

This discovery led me to replace the logging section with an interactive method that allowed students to set goals at the beginning of the week with the incentive of a small reward on Friday. The goal-setting section plays an integral role in creating a studentcentered approach as well as focusing on the emotional aspect of learning unconventionally. By allowing the student to set their own goal and incentive at the beginning of the week, students are able to create their own definition of success on an individual level, rather than reaching a standard set by other parties seen in Image 2 . However, through the interviews, I realized that the parents and the teachers' role was vital to setting the goal and ensuring that it would be met. Therefore, I put in place a star system that allows the parent and teacher to record whether or not the student is taking steps towards reaching their weekly goal. One of my interviewees shared:

He likes spending time outside or going to dinner, he just wanted to go out, just little things. Just a small thing that will help them strive towards success. (Interviewee C)

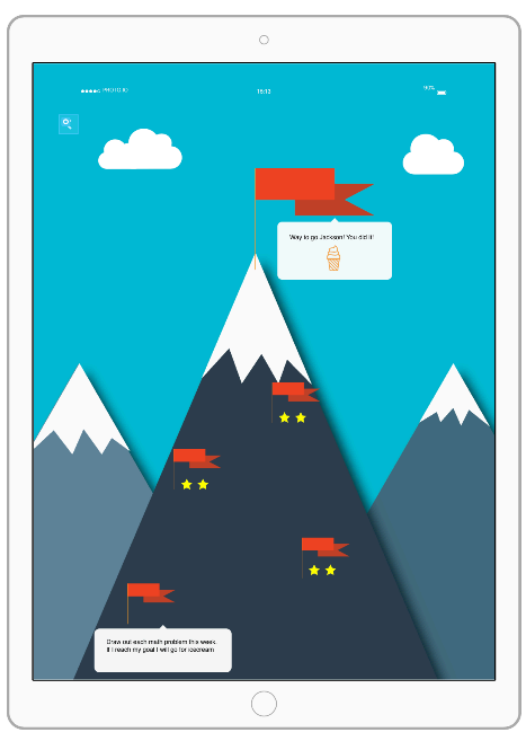

Each day the student takes noticeable steps towards reaching their Image 2- Goals goals, their teacher and parent will add a star in the goal tracker. This system will allow the student to track their goals, while ensuring the support of the parent and teacher. Furthermore, teachers explained that, while using other educational platforms, they struggled to get their students to use the service, conversely, after looking into the 
platforms that they listed it was clear that all of these platforms lacked engaging interaction that would interest students.

\section{Student Engagement and Interactivity}

Further, all the parents explained that interactive platforms seemed to hold their child's attention throughout the learning process at home, for instance interviewee A explained,

When he does his work online he never has an issue because he can interact with what he's doing. (Interviewee A)

Interviewee E continued to explain,

My school uses Google Drive to communicate with the students but I would say maybe only one or two use it to contact me and share ideas. I don't even know if they'd use a platform because they don't seem to use what's currently available to them. (Interviewee E)

From that insight, I decided to design the goals section and announcements as an interactive experience that would grasp the student's attention and involve engagement. With this in mind I designed the goal section as a mountain range with five red flags ascending up the mountain used to indicate the five days in a school week. The first flag represents Monday; the day in which the student sets their goal and incentive, as the day's

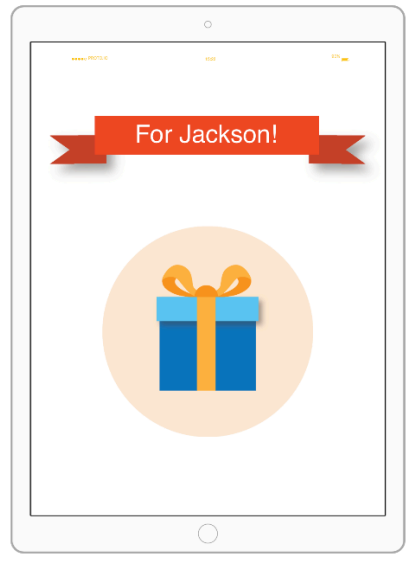

Image 3-Announcements progress, the number of flags increase journeying up the mountain. Each day that the student takes noticeable steps towards reaching their goal, their teacher and parent add a star under the flag. Friday is marked by a large red flag at the top of the mountain, and if the student has met their goal for the week they receive a message that congratulates 
them on reaching their goal and earning their prize. With the same notion of engagement and interactivity in mind, I decided to alter the perception towards announcements. Usually, when a student hears that their teacher has an announcement, regardless of what the announcement is, the initial thought is "test" or perhaps "test results." This can draw on feelings of past failures or the notion that nothing good can come from a message sent home from the teacher. With this in mind, I attempted to alter the perception towards receiving an announcement. Therefore, when the student receives a notification under announcements, once they have clicked the icon, they will have redirected to a page that has gift in the middle of the screen, with a banner that says "for you." Each time the student receives an announcement notification they will be given a gift that has a different size, shape and wrapping. The engagement aspect is based on the consistent change of the gift, and the anticipation of what might be inside.

\section{Functionality}

According to How to Find Buried Treasure Using Experience Maps by Conifer Research (2002), the experience model provides a step by step approach to create a successful user-experience, the steps include Entice, Enter, Engage, Exit, and Extend. The entice stage builds anticipation and sets the level of expectation for the user's. In this step the users of In-Touch will be attracted to platform that will foster the learning needs of their students and children in an innovative and interactive experience. Next, the enter stage takes place as the students, teachers and parents begin to interact with the platform. The engage stage appeals to the senses and creates a connection with 
the users through interactivity of the app. Through the navigation of the platform, the goals and announcements areas students will be able engage and interact with the functionalities that In-Touch provides. In addition, the exit phase of the model is described as "signposts guide you to a new, transformed sate" (Conifer Research,2002, p.2). With this in mind when the student is finished using the platform they have learned from the experience which leads to the extend phase which is described as "reminder's keep you connected to the experience" (Conifer Research,2002, p.2). This phase is represented by the application of the learning done within In-Touch when the student returns to the classroom. As mentioned earlier, the combination of formative assessment within In-touch outside of classroom hours will affect the student's performance within classroom hours, as they will apply what they've learned to their learning when they return to the traditional classroom.

Before I began choosing colours and creating icons, I began with sketches of wireframes to get a better understanding of navigation and accessibility. During this process, I had to keep in mind how each page would connect to another from the point of view of the users. Essentially, I was trying to tell a story of how a user, whether a parent, teacher, or student, would begin at the login page and journey through the platform. At first, I was in the mindset of branding the entire app in orange and blue, however as I continued to develop the design I started to add small burst of different colours. This addition of other colours added to the overall look of the app and created more balance, rather than over saturating the branding in one texture and two colours. Additionally, I realized that I was designing this platform for children, therefore, I utilized 
large and colourful icons, instead of words, to assist in the navigation and comprehension of the platform. The elements of colour, shadowing, size, and texture brought life and engagement to the platform by establishing In-Touch as a welcoming, safe space.

\section{Conclusion}

In sum, In-Touch facilitates the needs of unconventional learners and embodies a learning experience that is crafted with compassion for the individual learner. Within this paper, I have identified three pivotal features that form the framework of my design approach in this project: on-demand help, the student-centred approach and the emotional aspect of learning unconventionally, that are essential to securing a safe and encouraging learning environment. Through research it is apparent that an instructor must understand the importance of individualized teaching as well as the emotional strain of unconventional learning in order to create a teaching approach that resonates with the student. Those who learn through unconventional methods require a different approach to learning that is not offered in conventional schooling and certain measures must be taken to ensure a fruitful learning experience for everyone. In-Touch is used in the process of crafting the experience for the individual by recognizing that learning unconventionally goes beyond the act of teaching and explanation but relies on understanding, patience and compassion. Through In-touch the teacher, parents, and student will have an open line of communication that will help the instructor understand the individuals learning experience, craft a student-centered teaching approach as well as offer emotional support and encouragement. My hope is to help unconventional 
learners view themselves as valuable and intelligent individuals with much to offer and In-Touch is one step in making that aspiration a reality. 


\section{Appendix A}

The Shannon and Weaver Model of Communication

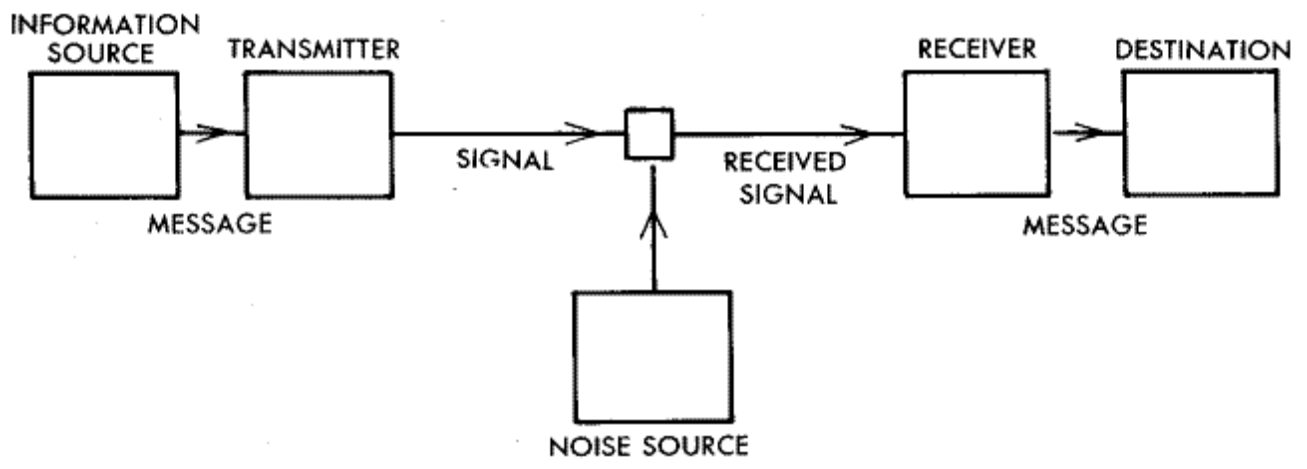




\section{Appendix B}

List of Questions

\section{Directed to both parties}

1. To begin, I would like to know what the term "unconventional learning" means to you?

\section{Probing Questions}

What do you associate the term with?

What kind of person do you associate with the term?

What were your personal experiences with what you are describing?

2.

Would you say that common classroom experiences in Toronto are sufficient to accommodate alternative learners? What was your experience in that area?

\section{Directed to parents}

How does your child approach do their homework?

Do you feel like you always need to be involved?

What are some emotions that you associate with helping your child with their homework?

What emotions do associate with your child's relationship to learning?

What do you do to help your child when they are struggling with their homework?

What were some indications that your child learned unconventionally?

How does your child learn best?

How can this be implemented into a digital platform?

How does your child best express their thoughts? Ex. Drawing, speaking?

How could audio or visual aid affect your child's approach to learning?

Explain your involvement in your child's learning process? Do you know what they are currently learning in school? Are you aware of what subjects they are struggling in?

Have you identified a pattern in the subjects your child succeeds in and struggles with?

What relationship do you have with your child's teacher? Do you discuss your child's success? Failures? areas of weakness and strength?

What kind of help do you wish you had?

Walk me through the process of helping your child with their homework? Do you feel equipped to answer their questions? 
Do you feel like you have a thorough of understanding of the way in which your child learns? What are some patterns that you notice?

Directed to those with experience teaching unconventional learners

How do you identify students who learn unconventionally in your class?

What resources are given to aid students that learn unconventionally?

What resources are teachers given to accommodate students that learn unconventionally?

What do you wish you had?

How would you get those resources?

What steps must be taken in order to adapt a style of teaching to better help an unconventional learner?

What can teachers do to ensure that students are equipped to learn effectively beyond the classroom?

What would you need to make this a reality?

How do you feel about aiding students with learning outside of classroom hours?

On-Demand help refers to the student asking a question and the teacher responding quickly through the use of a digital system. What are your thoughts on on-demand help? Would you be willing to use a tool that used on-demand help?

How can In-Touch facilitate the needs of unconventional learners?

1. How do you feel an online platform can aid students who learn through different learning styles?

2. What should the platform focus on? Navigation? Comprehension? Communication? 


\section{Appendix C}

Consent Form

\section{Ryerson Studies}

Ryerson University

Consent Agreement

You are being invited to participate in a research study. Please read this consent form so that you understand what your participation will involve. Before you consent to participate, please ask any questions to be sure you understand what your participation will involve.

\section{[IN-TOUCH DIGITAL PLATFORM]}

INVESTIGATORS: This research study is being conducted by Angelique Paul from the Masters of Digital Media program under the direct supervision of Dr. Alexander Ferworn and mentorship of Alevtina Naumova at Ryerson University. If you have any questions or concerns about the research, please feel free to contact Angelique Paul at Angelique.paul@ryerson.ca.

\section{PURPOSE OF THE STUDY:}

This study is designed to collect data that will further aid in the development of my prototype for In-Touch digital platform for unconventional learners, and to further study the need for my platform. For the purpose of my project I define an unconventional learner as someone who learns through methods that are not currently offered in our school system. This lack of support usually results in students feeling unintelligent and isolated. Through investigation the common denominator between both the parents and alternative learners are the feelings of frustration and helplessness. To address this issue, I propose an online platform called In-Touch that extends the learning experience beyond classroom hours and serves as a safe space for the instructor to focus on a particular student and facilitate their needs. Unconventional learners often feel isolated and lack confidence in a large classroom setting. Asking questions in front of a room of students seeming to understand can be intimidating and position an individual as lesser or unintelligent. Through this platform student's will have the privacy and confidence to pose questions and receive feedback without calling the attention of their classmates. Additionally, through this line of communication the teacher has the opportunity to pinpoint problem areas and develop online assignments and questions that would address the problem area and in-turn add to the process of individualized learning. To collect this information, I intend to conduct 
one-on-one meetings with a total of twelve participants, either face-to face, via skype or over the phone. In-Touch is a tool used by the student and the educator to communicate outside of classroom hours. The interview will involve two parties; the parents of unconventional learners and those who have experience teaching unconventional learners. Parents are an integral factors of the learning experience; they are aware of what the student requires when they are learning in the home environment and how the student learns as an individual. Additionally, the input of those who have experience with unconventional learners will aid in the design and what is required to create a platform for students that learn unconventionally. All data acquired will be used to contribute to my Master's thesis.

WHAT YOU WILL BE ASKED TO DO [OR] WHAT PARTICIPATION MEANS:

If you volunteer to participate in this study you agree to:

Partake in a one-on-one interview representing a) a parent of an unconventional learner, b) someone who is not affiliated with a school board with two years of experience teaching a child that learns unconventionally or $\mathrm{c}$ ) an independent tutor of children that learn unconventionally. If you have agreed to meet face to face this study will take place at a private room in Ryerson University or in a library, or at a location of your choice. This interview will last between half an hour to an hour. During this interview you will be asked a series of questions that are related to the current method of learning and teaching that is currently offered in traditional classrooms, and how a digital platform can best suit the needs of unconventional learners. Additionally, you will be asked questions concerning the learning style and behaviour of students/ your children that learn unconventionally. Below are two sample questions; for parents and for those with experience teaching unconventional learners:

Question for teachers: On-Demand help refers to the student asking a question and the teacher responding quickly through the use of a digital system. What are your thoughts on on-demand help? Would you be willing to use a tool that used on-demand help?

Questions for parents: Explain your involvement in your child's learning process? Do you know what they are currently learning in school? Are you aware of what subjects they are struggling in?

Furthermore, you are welcome to attend the Ryerson Masters of Digital Media Poster presentation on August $23^{\text {rd }} 2017$ to see how your input has informed the design of InTouch.

\section{POTENTIAL BENEFITS:}

This study is dedicated to the research and design of an online learning platform, which extends the learning environment of a classroom into an intimate and safe space, customized around the individual needs of unconventional learners. I cannot guarantee, however, that you will receive any benefits from participating in this study. 
WHAT ARE THE POTENTIAL RISKS TO YOU AS A PARTICIPANT:

Due to the personal nature of the questions asked, you may reflect on unpleasant memories while responding to the interview questions. If you should feel discomfort you may skip answering a question or stop participation, either temporarily or permanently. Additionally, if you would like to withdraw your input in the study at any time, you are within your right to do so.

\section{CONFIDENTIALITY:}

While participating in this study your identity will remain confidential. After I have collected the information from all interviews I will keep the data until August 2019, if I decide to continue pursuing this project beyond my Master's program. I will not be collecting or recording any personal information that will directly identify you such as your name. In order to record the meetings, I will either type the discussion or use a digital recorder. All files will be password protected file and stored on my password protected computer. I will then delete the files off of the digital recorder's SD card to ensure that I am the only individual with access to the information shared within the interviews. When the allotted time has passed I will delete all audio and digital files from my computer. In addition, if there are any hard copy forms or data they will be shredded. By agreeing to participate in this research, you are not giving up or waiving any legal right in the event that you are harmed during the research.

\section{VOLUNTARY PARTICIPATION AND WITHDRAWAL:}

Participation in this study is completely voluntary. You can choose whether to be in this study or not. If any question makes you uncomfortable, you can skip that question and still participate. You may stop participating at any time. If you choose to stop participating, you may also choose to not have your data included in the study after the interview is completed. You may remove your data from the study by July $25^{\text {th }} 2017$. Your choice of whether or not to participate will not influence your future relations with Ryerson University or the investigator [Angelique Pau] involved in the research.

QUESTIONS ABOUT THE STUDY: If you have any questions about the research now, please ask. If you have questions later about the research, you may contact.

Angelique Paul at Angelique.paul@ryerson.ca, Alexander Ferworn at aferworn@ryerson.ca or Alevtina Naumova at alyaleka@gmail.com.

This study has been reviewed by the Ryerson University Research Ethics Board. If you have questions regarding your rights as a participant in this study, please contact:

Research Ethics Board c/o Office of the Vice President, Research and Innovation Ryerson University 350 Victoria Street Toronto, ON M5B 2K3 416-979-5042 rebchair@ryerson.ca 


\section{[IN-TOUCH DIGITAL PLATFORM]}

\section{CONFIRMATION OF AGREEMENT:}

Your signature below indicates that you have read the information in this agreement and have had a chance to ask any questions you have about the study. Your signature also indicates that you agree to participate in the study and have been told that you can change your mind and withdraw your consent to participate at any time. You have been given a copy of this agreement.

You have been told that by signing this consent agreement you are not giving up any of your legal rights.

Name of Participant (please print)

$\overline{\text { Signature of Participant Date }}$

I agree to be audio recorded for the purposes of this study. I understand how these recordings will be stored and destroyed.

Signature of Participant Date

I would like to be contacted about information regarding the MDM Poster Show on August $23^{\text {rd }} 2017$. 


\section{Work Cited List}

Aleven, V., Stahl, E., Schworm, S., Fischer, F., \& Wallace, R. (2003). Help seeking and help design in interactive learning environments. Review of educational research, 73(3), 277-320.

Bakula, Nora (2010). The Benefits of Formative Assessments for Teaching and Learning. Science Scope, 34(1), 37-43. Accessed May 13, 2017, https://csoscience.files.wordpress.com/2010/10/nsta_formative-assessment.pdf

Bryan, T., Burstein, K., \& Ergul,C. (2004). The Social-Emotional Side of Learning Disabilities: A Science-based Presentation of the State of the Art. Learning Disabilities Quarterly, 27(1),46. Accessed December $5^{\text {th }} 2016$,

Centre for Education and Research Innovation's: (2006). Assessment for Learning: Formative Assessment. N.A.

Chappuis, S \& Chappuis, J. (2007). Educational Leadership: The Best Value in Formative Assessment. Educational Leadership, 65(4), 14-19.

Cheek Brad., Rolfe Alexander. (2012). Education and Inspiration for General Practice: Learning Styles. Sage Journals, 5(3). Accessed May 13, 2017. 
Conifer Research (2002). How to Find Buried Treasure Using Experience Maps.

Retrieved from https://msu.edu/ jmonberg/491/User_files/ConiferExperienceMaps.pdf

Earle, Sarah (2014). Formative and summative assessment of science in English Primary Schools: evidence from the Primary Science Quality Mark. Research and Science and Technological Education,32 (2). Accessed April $20^{\text {th }}, 2017$, https://journals-scholarsportal-info.ezproxy.lib.ryerson.ca/pdf

Hannah Harwood., Nelson Jason M. (2011). Learning Disabilities and Anxiety: A MetaAnalysis. Journal of Learning Disabilities,44(1). Accessed May $13^{\text {th }}, 2017$.

Learning Disabilities Association of Ontario. Learning Disabilities Statics. Dec.2015. Web. 12 May. 2017.

Mcquail, D., \& Windahl, S. (1993). Communication Models for the Study of Mass Communication. Routledge Taylor \& Francis Group. 2, 17.

N.A. New Relic: 5 Key Phases in Creating a Successful Mobile App [Internet Article]. Retrieved from https://try.newrelic.com/rs/newrelic/images/AST0108050_New_Relic_WP_App_Design_093013_1_.pdf

Rosenquist, R.L. (2000). A Comparison of Learning Styles Between Alternative and Traditional Educators in the State of lowa (Doctoral Dissertation). Retrieved from lowa State University Digital Repository. Paper 13926. 
Toronto District School Board (2016, January). Toronto District School Board Financial Facts: Revenue and Expenditure Trends. Retrieved from http://www.tdsb.on.ca/Portals/0/AboutUs/Budget/FINAL\%20Financial\%20Facts\% 202016.02.05.pdf 